\title{
Behaviour-specific habitat selection patterns of breeding barn owls
}

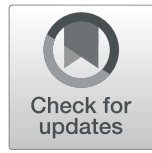

Robin Séchaud ${ }^{1 *}$ (D, Kim Schalcher ${ }^{1}$, Ana Paula Machado ${ }^{1}$, Bettina Almasi ${ }^{2}$, Carolina Massa ${ }^{1,3,4}$, Kamran Safi, ${ }^{5,6+}$ and Alexandre Roulin ${ }^{1+}$

\begin{abstract}
Background: The intensification of agricultural practices over the twentieth century led to a cascade of detrimental effects on ecosystems. In Europe, agri-environment schemes (AES) have since been adopted to counter the decrease in farmland biodiversity, with the promotion of extensive habitats such as wildflower strips and extensive meadows. Despite having beneficial effects documented for multiple taxa, their profitability for top farmland predators, like raptors, is still debated. Such species with high movement capabilities have large home ranges with fluctuation in habitat use depending on specific needs.
\end{abstract}

Methods: Using GPS devices, we recorded positions for 134 barn owls (Tyto alba) breeding in Swiss farmland and distinguished three main behavioural modes with the Expectation-Maximization binary Clustering (EMbC) method: perching, hunting and commuting. We described barn owl habitat use at different levels during the breeding season by combining step and path selection functions. In particular, we examined the association between behavioural modes and habitat type, with special consideration for AES habitat structures.

Results: Despite a preference for the most common habitats at the home range level, behaviour-specific analyses revealed more specific habitat use depending on the behavioural mode. During the day, owls roosted almost exclusively in buildings, while pastures, meadows and forest edges were preferred as nocturnal perching sites. For hunting, barn owls preferentially used AES habitat structures though without neglecting more intensively exploited areas. For commuting, open habitats were preferred over wooded areas.

Conclusions: The behaviour-specific approach used here provides a comprehensive breakdown of barn owl habitat selection during the reproductive season and highlights its importance to understand complex animal habitat preferences. Our results highlight the importance of AES in restoring and maintaining functional trophic chains in farmland.

Keywords: Agri-environment schemes, AES, Global positioning system technology, GPS, Home range, Path selection, Step selection, Tyto alba

\footnotetext{
*Correspondence: robin.sechaud@unil.ch

${ }^{\dagger}$ Kamran Safi and Alexandre Roulin are co-senior authors.

'Department of Ecology and Evolution, University of Lausanne, Building

Biophore, CH-1015 Lausanne, Switzerland

Full list of author information is available at the end of the article
}

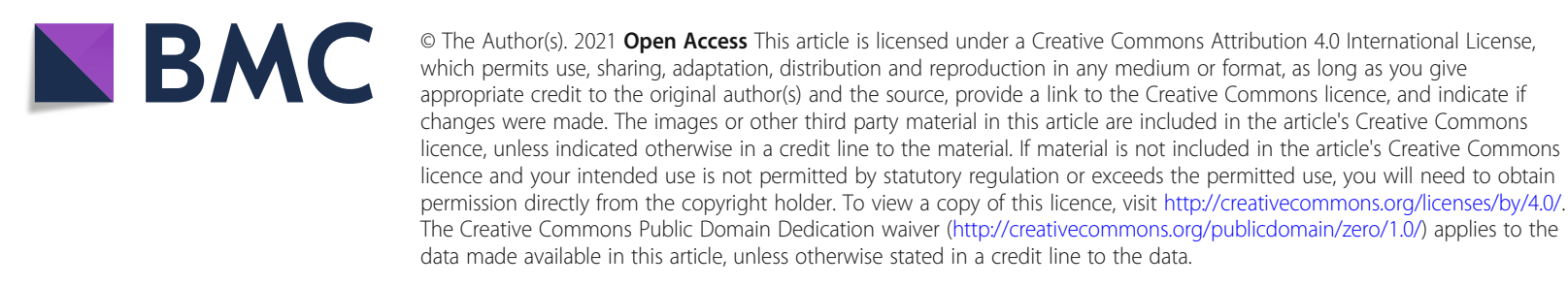




\section{Introduction}

The intensification of agricultural practices over the past century has severely changed European farmland $[1,2]$. Many animal and plant populations declined [3, 4], and agriculture itself is suffering from the loss of services provided by wild organisms, such as crop pollination [5]. To counter the strong decrease in farmland biodiversity, European countries have adopted agri-environment schemes (AES), consisting mainly of paying direct subsidies to farmers to implement environmentally friendly farming practices. Despite documented beneficial effects on plant, insect and small mammal densities and on species richness [6-8], the effects of AES for larger vertebrate species remain unexplored. Probably the wide range of habitat used and movement capabilities render these species difficult to study. However, ensuring the presence of large vertebrate species, such as raptors, is an important step in the process of restoring and maintaining functional food chains in farmland ecosystems [9].

Distinguishing fine scale habitat preferences associated with different behaviours is key for understanding the underlying biological processes that drive animal movement [10]. How an animal uses its habitat is a complex decision-making process that can fluctuate with various factors, such as food availability [11], season [12], and individual life history traits [13], but also with the spatial and temporal scale considered $[14,15]$. Habitat selection based on different behavioural modes has so far received limited attention, but the recent development in animal tracking technologies generated the opportunity to collect GPS locations at a high enough frequency to infer an animal's behaviour from it [16-18]. Including a behavioural component in habitat selection analyses may be particularly valuable for depicting behaviour-specific selection patterns and consequently for improving prioritization in habitat management and conservation $[10,19]$.

The barn owl (Tyto alba), a raptor hunting small mammals in farmlands, suffered a rapid decline across Europe, mainly due to the spread of urbanization and the intensification of farming practices affecting the availability of nesting sites and quality of foraging habitats $[20,21]$. While providing nest boxes relieved the shortage of secure breeding sites, the knowledge on habitat requirements is still patchy. A previous study did not find any association between nest box occupancy, reproductive success and the surrounding habitats [22], indicating that habitat preferences may occur at a finer scale within the home range. In a radio tracking study, Arlettaz et al. (2010) showed that foraging activity was more intense in cereal crops and grasslands than in more extensively exploited areas, suggesting that AES could be less important for farmland raptors than suspected.
Here, to explore the association between behavioural modes and habitat structure, we studied behaviourspecific habitat selection in wild barn owls breeding in an intensive agricultural landscape in western Switzerland. We expect barn owls to select different habitat structures according to the needs associated to the different behavioural modes. Over 2 years, we equipped barn owl breeding pairs with GPS devices. Combining the high location sampling rate with a behavioural segmentation method, we distinguished three main behavioural modes - perching, hunting and commuting - and related them with habitat use. These behavioural modes represent three main movement behaviours displayed by barn owls outside of their nests (their definition and manner distinction are further explained in the methods). To appropriately evaluate the use of rare and scattered habitats, as is the case with AES, we used step and path selection functions, which define the habitats available to an animal according to its current location. In this context, AES habitats might not be recognisably selected at the home range level but they can still be important components of barn owl behaviour-specific habitat use and possible key elements for farmland raptors.

\section{Materials and methods}

\section{Study area and barn owl population monitoring}

The study was carried out in 2016 and 2017 in a 1,000 $\mathrm{km}^{2}$ intensive agricultural landscape in western Switzerland where a wild population of barn owls breeds in nest boxes attached to barns [22]. In the first 2 weeks after hatching, the adult females remain almost entirely in the nest to provide warmth to their offspring and distribute the food among them brought by the male. After this period, both parents hunt small mammals, the male being the main contributor to the feeding of the nestlings [23].

\section{GPS tags and deployment}

We used GiPSy-5 GPS tags (Technosmart, Italy) weighing approximately $12 \mathrm{~g}$ including battery (less than $5 \%$ of the owl body mass; in our population, body mass ranged from 251 to $393 \mathrm{~g}$ ), measuring 30x20x10 mm including the battery, and coupled with a $40 \mathrm{~mm}$ long antenna. They were attached as backpacks with a Teflon harness. Each tag collected location and time every $10 \mathrm{~s}$, from 30 min before dusk until $30 \mathrm{~min}$ after dawn, covering the entire owl nocturnal activity period.

Breeding barn owls were captured at their nest site when the oldest offspring was 25 days-old on average $(\mathrm{SD}=2.8)$, equipped with GPS tags and released at the capture site. We recorded adults' sex and age (categorized as yearlings or older birds). Approximately 2 weeks later, the owls were recaptured and the GPS tags 
recovered. The deployment of GPS tags corresponds to a period of intense habitat use by the parents to feed their nestlings, while being in accordance with ethical (earlier captures could lead to the abandonment of the clutch) and methodological constraints (later recapture could be compromised due to changes in food provisioning behaviour). Prior to any analysis, the 134 GPS tracks (72 males and 62 females) were filtered for aberrant positions using speed (excluding locations with a speed higher than $15 \mathrm{~m} / \mathrm{s}$ ) and location (excluding locations outside the study area). From the 1,924,623 collected positions, 1,922,636 were kept for the following analyses (1987 removed).

\section{Habitat monitoring}

Once a barn owl breeding pair was equipped with GPS tags, we mapped the habitat at high-resolution in a radius of $1.5 \mathrm{~km}$ around the nest site and stored the surveys in QGIS v.2.18.13 [24]. The $7 \mathrm{~km}^{2}$ mapped corresponded to barn owl home range sizes reported in the literature (range: $0.9-8.1 \mathrm{~km}^{2}$ ) [21, 23, 25]. When barn owls travelled out of the area initially mapped, we went to the field to map it shortly after the GPS tag recovery. We adopted a 10-category habitat classification (Table S1), with 6 categories recorded directly in the field - cereals, root vegetables (sugar beets and potatoes), pastures, intensive meadows, extensive meadows and wildflower strips - and the four remaining categories - forests, forest edges, roads and settlements - were derived from the swissTLM ${ }^{3 \mathrm{D}}$ catalogue (Swiss Topographic Landscape Model). The cereals, root vegetables, intensive meadows and pastures habitat categories represent the intensive agricultural land use, whereas the wildflower strips and extensive meadows are AES implemented in the area to preserve and promote biodiversity in farmland (Table S2). Forests are common structural components of this landscape, and their edges are transitional zones between the forested areas and the crops. Finally, the farmland landscape is interspersed with anthropogenic constructions, which are represented here by the road and settlement habitat categories.

\section{Behaviour annotation}

Barn owl movement data were classified into different behavioural modes using the Expectation-Maximization binary Clustering (EMbC) method implemented in the $E M b C$ package [18]. EMbC is an unsupervised algorithm that clusters movement data based on speed and turning angle between locations. The three behavioural modes distinguished were perching, hunting and commuting. Perching, as a stationary behaviour, was characterized by low speed and a wide range of turning angles due to little GPS location errors. Hunting was characterized by low-medium speed and medium-high turning angles, whereas commuting was characterised by fast and straight flights. For validation, the EMbC behavioural classification was confronted to a visual classification performed on the tracks of 20 individuals. We found an average match of $92.7 \%$ between the visual and the $\mathrm{EMbC}$ classifications (perching: mean $=94.5 \%, \mathrm{SE}=2.3$; hunting: mean $=92.6 \%, \mathrm{SE}=4.9 ;$ commuting: mean $=$ $91.1 \%, \mathrm{SE}=3.8$; San-Jose et al. 2019). These and all subsequent analyses were conducted with R v3.5.1 [26].

\section{Home range size and composition}

Home range size was calculated using a 95\% kernel density estimator method [27]. To deal with temporal auto-correlation between data points, we used the continuous-time movement modelling package ( $\mathrm{ctmm}$ ) [28] to calculate home range size via auto-correlated kernel density estimation (AKDE) [29]. The ctmm model was calibrated using User Equivalent Range Error (UERE), estimated with location data obtained by fixed GPS devices in open landscape. Model parameters with better fit were chosen automatically with the function variogram.fit in the ctmm package [28]. Barn owl home range composition was obtained by extracting the relative abundance of the 10 habitat categories contained in each home range.

We modelled the effect of sex and age, as well as year and date of GPS data collection, on the home range size of the barn owls using a linear mixed-effect model parametrized with the lmerTest package [30]. The home range size was log-transformed and the brood ID, grouping owls belonging to the same brood, set as random factor. For all linear mixed-effect models used in this paper, we checked for collinearity between predictors and verified the assumptions of Gaussian error distribution by visually inspecting residual diagnostic plots.

\section{Habitat selection \\ Home range selection}

Home range selection (positioning of the home range in the landscape) compared the composition of the habitats available in the landscape, defined as the habitats contained in the $1.5 \mathrm{~km}$ radius around the nest site, with the ones contained in the home ranges (third-order selection; [31]), using ADEhabitatHS package [32]. For this and all subsequent analyses, selection ratios were estimated for each individual and habitat category, and then averaged to obtain the population's habitat selection estimates. In addition, when some habitat selection coefficients were poorly estimated (because the habitats were absent or rare), we re-ran the model without the problematic habitat category to avoid misestimating the other selection estimates (Table S3). 


\section{Roosting and perching site selection}

Roosting and perching site selection were analysed separately, with the former representing the sites used for hiding and resting during the day and the latter the sites used to perch during the night-time activity. Roosting site selection analyses compared the roosting sites' habitats used to the ones available in the home range (thirdorder selection; [31]).

Perching site selection analyses compared night perching sites' habitats to the ones available in the home range (third-order selection; [59]). Rather than considering each perching location point independently, they were grouped into perching events. As the choice of a perching site may depend on the surrounding landscape (perching sites corresponding to the nest site were excluded from the analyses), the habitat types present within a $100 \mathrm{~m}$ radius around the perching site were extracted.

\section{Hunting ground selection}

We parametrized a step selection function (SSF) to identify how habitat influences barn owl hunting movements [33]. The SSF considers the choice made by the animal at each step by comparing the observed step to a set of alternative ones, thus redefining the available habitats at every step. Using the ctmm.fit function in the ctmm package [28], we calculated that 30-s step time intervals were characterised by weak autocorrelation between steps, while maintaining sufficient resolution to address how habitat is selected during hunting. Once thinned to 30-s intervals, each observed step was paired with 100 alternative steps generated by randomly picking the step lengths (distance between successive locations) and turning angles (change in direction between steps) from the distribution of these parameters for the entire population using the amt package [34]. The habitat at the end point of each of these alternative steps was extracted. To compare habitat characteristics of observed and random steps, we ran a conditional logistic regression with amt's fit_clogit function. The models contained 8 habitat categories - cereals, root vegetables, forests, forest edges, intensive meadows, extensive meadows, pastures and wildflower strips - as well as three movement parameters - step length, log of the step length and the cosine of the turning angle -known to render the estimates of the habitat regression parameters more robust $[35,36]$. Including these movement variables as predictors allow to model both movement and habitat selection processes into an integrated step selection function [36]. The step and burst IDs were entered as strata in the model, the first one to link the real and the 100 alternative steps and the second one to group the steps belonging to the same track. Two habitat categories - roads and settlements - were not included in the models because they were too rare in the dataset and prevented the models from converging.

To investigate if the similarity in habitat selection coefficients between individuals was related to seasonality and individual factors, we used a non-metric multidimensional scaling approach (NMDS; [37]). NMDS is a rank-based ordination method that uses pairwise distances between objects or individuals, and represents them in a low dimensional space. Using the coefficients of selection, a dissimilarity matrix was built with the Bray-Curtis method using the function metaMDS in the vegan package [38]. The wildflower strips habitat category was removed from this analysis because the limited number of coefficients obtained was not sufficient to parameterize a valid NMDS model (Table S3). To investigate if the year and date of GPS data collection, as well as the sex and the age of the owl, could explain the similarity or differences between birds in the classification proposed by the NMDS, we ran a permutation test using the envfit function in the same package with 10, 000 permutations. We included in the model the year and date of GPS data collection as proxies for temporal variations in the landscape structure and profitability.

\section{Commuting path analyses}

Commuting tracks were classified in three main categories, each with a different purpose. The first type of commuting flight takes place when an owl leaves its nest box to reach a hunting ground or a perching spot. The second one is the reverse, when the owl catches a prey item and returns to the nest box to feed its nestlings. The third type of commuting is used to move within the landscape, to travel between hunting or perching sites, and is independent from the nest box location.

We built a path selection function (PathSF) to investigate the influence of landscape on commuting flights [39]. In PathSF, the entire path is the unit of measurement and, in a similar fashion to SSF, is compared to randomly generated paths. We discarded the commuting to and from the nest box to avoid the bias associated to the habitats surrounding the nest box location, and therefore considered only the commuting flights within the habitat. For each observed path, 20 alternative paths were generated by first randomly relocating the starting point of the path within a radius of $1.5 \mathrm{~km}$, and then by rotating it by a random angle between 0 and 360 degrees [39]. Habitats contained in a $20-\mathrm{m}$ buffer along the tracks were extracted and, to compare observed and random paths, conditional logistic regressions were built using the fit_clogit function in the amt package [34]. For statistical purposes, we grouped cereals, vegetable roots, pastures and intensive meadows into an "intensive open habitats" category, while the categories extensive meadows and wildflower strips were aggregated into 
"extensive open habitats". We built conditional logistic regression models containing intensive open habitats, extensive open habitats, forests, forest edges and roads as explanatory variables, and the burst ID as strata. Settlements were excluded from the analyses because they were under-represented in the extracted habitats and caused models to not converge.

For each of the three commuting flight types, the deviation from the straightest path was measured as the difference between the length of the real track and that of the shortest path between the starting and ending point of the commuting event. To test if the distance covered, the deviation from the straightest path, and the speed (calculated as the distance covered divided by the time) differed between the three types of commuting, we ran linear mixedeffect models using the lmerTest package [30]. The distance covered and the deviation from the straightest path were log-transformed. The type of commuting was entered as an explanatory variable and the bird identity set as random factor.

\section{Results}

\section{Behaviour characteristics and activity period}

For the 134 individuals considered (72 males and $62 \mathrm{fe-}$ males), the number of nights with data recorded varied between 4 and 15 (mean =9.9; $\mathrm{SD}=2.1$ ) and the time interval between each location was $9.9 \mathrm{~s}$ on average $(\mathrm{SD}=1.3)$. Behavioural annotation of the GPS tracks (sampling every $10 \mathrm{~s}$ ) revealed great differences in step lengths and turning angles between perching, hunting and commuting behavioural modes (Fig. S1). Hunting flights were performed at an average speed of $4.9 \mathrm{~m} / \mathrm{s}$ ( $\mathrm{SD}=1.0$; range: $1.7-12.2 \mathrm{~m} / \mathrm{s}$ ), while the mean speed of commuting flights was $6.6 \mathrm{~m} / \mathrm{s} \quad(\mathrm{SD}=1.1$; range: $2.4-$ $13.4 \mathrm{~m} / \mathrm{s})$. Occasionally, owls flying at speeds above 10 $\mathrm{m} / \mathrm{s}$ were recorded when commuting $(\max =13.4 \mathrm{~m} / \mathrm{s})$, for a flight duration from $50 \mathrm{~s}$ to $9 \mathrm{~min}$ (Fig. S2).

The nightly activity period, defined as the time between two daylight roosting events, varied from $5.4 \mathrm{~min}$ to $10.4 \mathrm{~h}$ (median $=6.8 \mathrm{~h}, \mathrm{SD}=2.1$; Fig. S3). During their activity period, barn owls perched on average $77.5 \%$ ( $\mathrm{SD}=13.8$; range: $14.6-100 \%)$ of the time, while the rest was composed of $12.7 \%$ of hunting $(\mathrm{SD}=9.4$; range: 0 $75.2 \%)$ and $9.8 \%$ of commuting ( $\mathrm{SD}=7.4$; range: 0 53.3\%; Fig. S4).

\section{Home range size and composition}

Home range size varied significantly (mean $=6.6 \mathrm{~km}^{2}$; range: 0.96-25.46; Fig. S5), with males having smaller home ranges than females. On the other hand, neither age, year nor date were related to the home range size (Table 1).

Despite large inter-individual variations (Fig. 1), barn owl home ranges contained consistently and
Table 1 Effect of individual and time parameters on barn owl home range size. Results from a linear-mixed model on 134 logtransformed home range sizes from 83 broods (set as random factor)

\begin{tabular}{lllll}
\hline Parameter & Estimate \pm SE & df & t-value & $\boldsymbol{p}$ \\
\hline Intercept & $2.028 \pm 0.120$ & 120.76 & 16.94 & $<0.001$ \\
Sex $^{\mathrm{a}}$ & $-0.440 \pm 0.102$ & 68.77 & -4.32 & $<0.001$ \\
Date $^{\mathrm{b}}$ & $-0.032 \pm 0.061$ & 86.55 & -0.53 & 0.598 \\
Year $^{\mathrm{a}}$ & $-0.166 \pm 0.122$ & 75.38 & -1.37 & 0.176 \\
Age $^{\mathrm{a}}$ & $-0.135 \pm 0.117$ & 128.90 & -1.16 & 0.249 \\
\hline
\end{tabular}

a Males minus females; 2017 minus 2016; older birds minus yearlings

${ }^{b}$ The Date parameter was scaled

predominantly intensive agricultural fields $(24.6 \%$ of cereals, $11.5 \%$ of intensive meadows, $10.4 \%$ of root vegetables and $7.1 \%$ of pastures). The forested areas were the second most represented habitat class $(18.1 \%$ of forest and $5 \%$ of forest edges), followed by human-made constructions (10.9\% of settlements and $8.4 \%$ of roads). Finally, extensively exploited areas were the rarest habitat class, with $4.1 \%$ of extensive meadows and $0.5 \%$ of wildflower strips. In addition to being the rarest habitat, wildflower strips were also absent in $21 \%$ of the home ranges (Fig. 1).

\section{Home range selection}

At the home range level, habitat selection revealed that barn owls incorporated in their home range some habitat types in disproportion compared to surrounding landscape (Fig. 2a). Intensive meadows and cereals were found in higher proportion in home ranges than in the nearby landscape, whereas settlements and forests were

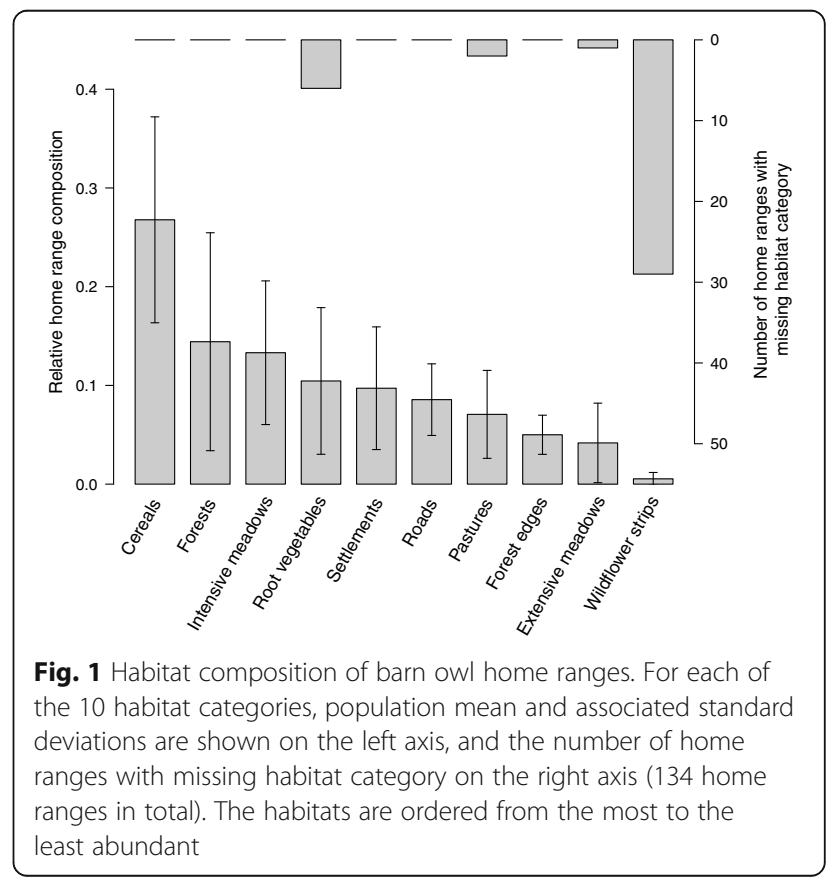




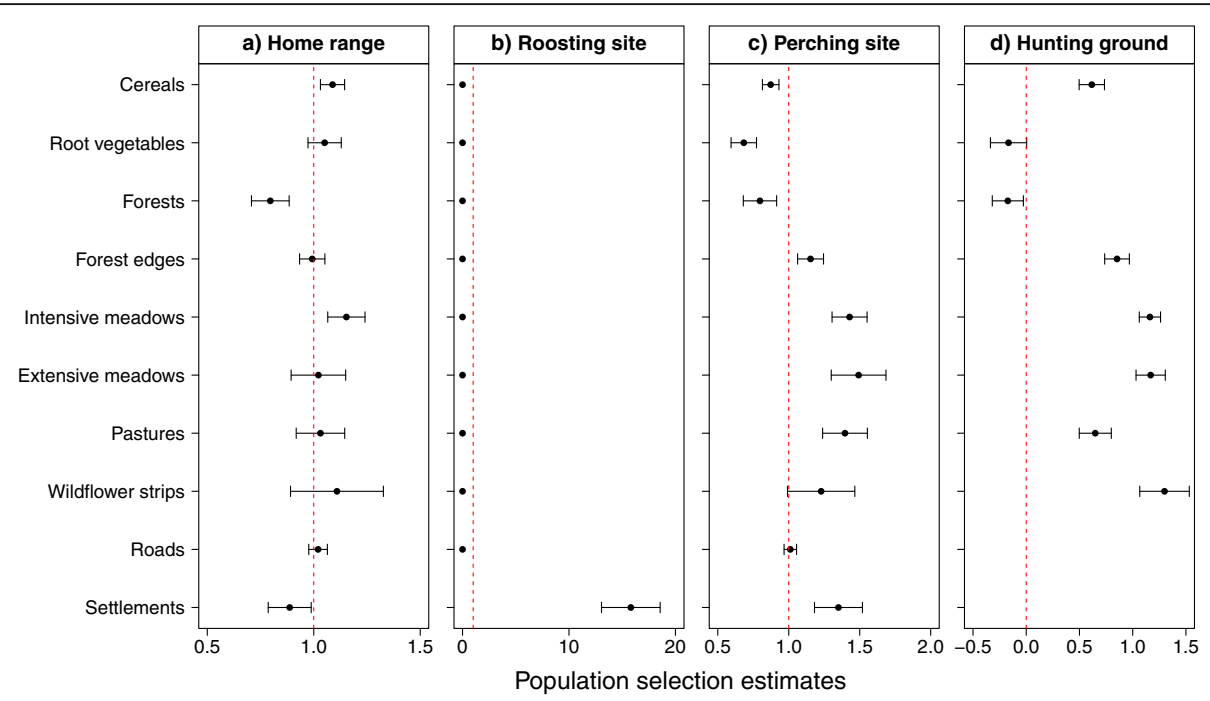

Fig. 2 Habitat selection population estimates. Home range composition, roosting and perching site selection analyses were computed following the Manly's third-order selection approach. Hunting ground selection followed the step-selection function (SSF) approach. Models were run for every individual and then averaged to obtain population estimates (mean and associated $95 \%$ confidence intervals are shown). Estimates on the right and left side of the dotted red line indicate, respectively, selected and avoided habitats

included in the home ranges in a smaller proportion than available. The selection ratios for the other habitat categories did not differ significantly from random use.

\section{Roosting and perching site selection}

Over the 915 daylight roosting events identified, 909 were located in barns or farms (468 in the nest box or in the nest box building, 441 in another building) and 6 were in forested areas, resulting in a clear selection pattern for settlements and avoidance of all 9 other habitat types (Fig. 2b). Roosting in natural habitats is thus an extremely rare event, concerning here 3 different females (out of 134 birds).

Overall habitat selection for night-time perching showed a clear pattern of habitat selection and avoidance (Fig. 2c). Among the habitats selected for perching, extensive meadows had the highest selection ratio, followed by intensive meadows, pastures, settlements and forest edges, while cereals, root vegetables and forests were avoided. Finally, roads and wildflower strips' selection ratios indicated a use according to their availability.

\section{Hunting ground selection}

The hunting SSF model revealed clear differences in selection ratios between the different habitat categories (Fig. 2d). Hunting owls avoided forests, and the root vegetables to a lesser extent, while selecting all six remaining habitat categories. Among the selected habitats, wildflower strips, extensive and intensive meadows were the most preferred ones, followed by forest edges, pastures and cereals. The scaled averaged estimates of the three movement parameters included in the models to increase the robustness of the habitat estimates were 0.04 for the cosine of the turning angle $(\mathrm{SD}=0.15)$, 0.10 for the step length $(S D=0.39)$ and 0.21 for the $\log$ of the step length $(\mathrm{SD}=0.53)$.

The three-dimensional NMDS model was associated with a stress value of 0.15 , indicating a reliable representation of the coefficients of selection (Fig. S6). The first NMDS dimension contrasted between intensive meadows to root vegetables and forests, the second distinguished the forests, and the third one the root vegetables (Table S4). We tested if the similarity in habitat selection between individuals was related to the year and date of GPS installation, two proxies for structural and qualitative modifications of the landscape, and the owl sex and age, two parameters associated with individual investment and hunting experience. The permutation test showed a significant effect of the date $\left(r^{2}=0.24\right.$, $p<0.001)$, whereas the year $\left(r^{2}=0.02, p=0.19\right)$, sex $\left(r^{2}=0.03, p=0.12\right)$ and age $\left(r^{2}=0.03, p=0.11\right)$ showed no significant relationship with hunting coefficient variations. The dimensions 2 and 3 of the NDMS encompassed most of the effect of the date $(\mathrm{NMDS} 1=-0.16$, NMDS2 $=0.59$, NMDS3 $=-0.79$ ), indicating higher root vegetable selection ratios at the end than at the beginning of the season, whereas the opposite was observed for forests (Fig. 3).

\section{Commuting path analyses}

The within habitat commuting PathSF model showed that all habitats considered were used for commuting, except for forest which was clearly avoided (Table 2). Considering 


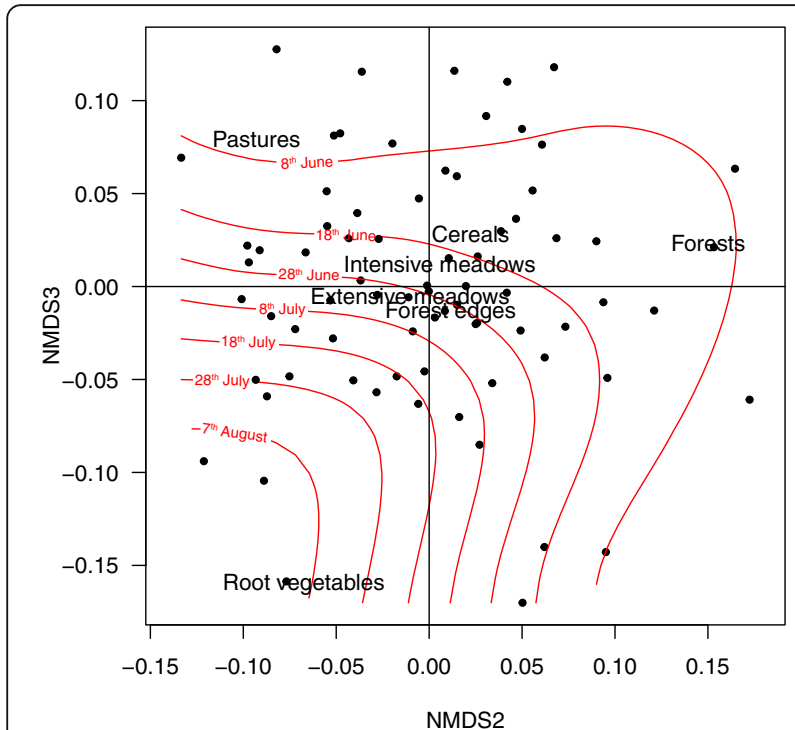

Fig. 3 Non-metric multi-dimensional scaling (NMDS) plot of hunting habitat selection estimates, each dot representing an individual. The effect of the date (in red) in the dimensions 2 and 3 (encompassing most of the date influence) is shown. Habitat categories are plotted for ease of understanding

all commuting flight types, owls covered a median distance of $447.7 \mathrm{~m}$ (range: 97.9-3676.1). The longest commuting flights were performed when returning to the nest, followed by the flights to leave it and the smallest distances covered were within the habitat (Fig. 4a, Table 3). When commuting, owls deviated $20.5 \mathrm{~m}$ (range: $0.1-$ 991.2) on average from the most direct path. They deviated more from the straightest path when leaving the nest box than when they commuted in the habitat (Fig. 4b, Table 3). When commuting, owls flew at an average speed of $6.5 \mathrm{~m} / \mathrm{s}$ (range: $3.4-13.4$ ). They commuted the fastest to return to the nest box, followed by leaving it, and lastly within the habitat (Fig. 4c, Table 3).

Table 2 Commuting path selection. Using the path selection function approach (PathSF), selection ratios for each individual and habitat were extracted from a conditional logistic regression model including the five habitat categories listed and the burst as strata. Mean population selection estimates and associated $95 \% \mathrm{Cl}$ are shown, and the habitats are ordered from the most to the least preferred

\begin{tabular}{llll}
\hline Habitat & Selection ratio & Lower $\mathbf{C l}$ & Upper Cl \\
\hline Open intensive habitats & 2.10 & 1.70 & 2.50 \\
Roads & 1.69 & 0.87 & 2.51 \\
Open extensive habitats & 1.52 & 1.04 & 2.01 \\
Forest edges & 1.05 & 0.24 & 1.85 \\
Forests & -0.61 & -1.19 & -0.03 \\
\hline
\end{tabular}

\section{Discussion}

In the context of preserving biodiversity in farmlands, our study provides a comprehensive breakdown of barn owl habitat selection during the reproductive season. The various behaviour-specific habitat analyses highlight the complementarity of this approach in understanding complex animal habitat preference and for proposing targeted conservation actions.

With an average size of $6.6 \mathrm{~km}^{2}$, the home range sizes obtained in our study correspond to the ones previously described for barn owls in Europe [21, 25, 40, 41]. In this species, parental investment varies between sexes [42, 43], which is consistent with our finding that males had smaller home ranges than females. The bigger home range of females could be explained by double-brooded females which often desert their first brood to start a new one elsewhere with another mate [42, 44]. To find a new partner, females may prospect large areas, while their first male is still hunting close to their first nest.

Forested areas, commonly known to be avoided by barn owls, were under-represented in barn owl's home ranges, probably because its morphology (i.e. short tail and long wings) and hunting-on-the wing technique limits its use of closed habitats [21, 23]. Thus, home ranges contained mainly open habitats, with the most common ones - cereals and intensive meadows - being preferentially included (Fig. 2a). AES habitat categories were not selected at the home range level. Increasing the proportion of AES, the least represented habitat with low connectivity between each patch, in the home range likely implies the inclusion of the more abundant habitat categories.

Despite selection at the home range level being characterized by a preference for the most common habitats, behaviour-specific analyses revealed distinctive habitat use depending on the behavioural mode. During the day, barn owls roosted almost exclusively in buildings despite the apparent availability of natural sites (Fig. 2b). They might use the urban environment to shelter against adverse weather conditions, minimize the energy invested to thermoregulate and reduce the risk of predation or disturbance by competitors $[45,46]$.

During the night, barn owls preferred to perch in meadows, pastures, settlements and along forest edges (Fig. 2c). Perching habitat selection pattern was fairly similar to that of hunting, hinting at the use of the sitand-wait hunting technique seen in many raptors [21, 47]. It may also reflect an opportunistic behaviour, in which resting or preening close to hunting grounds could offer the opportunity to capture a prey [48, 49]. In addition to the natural perching sites, barn owls also benefit from the fencing of pastures and artificial poles that are installed by farmers to attract raptors as pestcontrol agent [50]. 

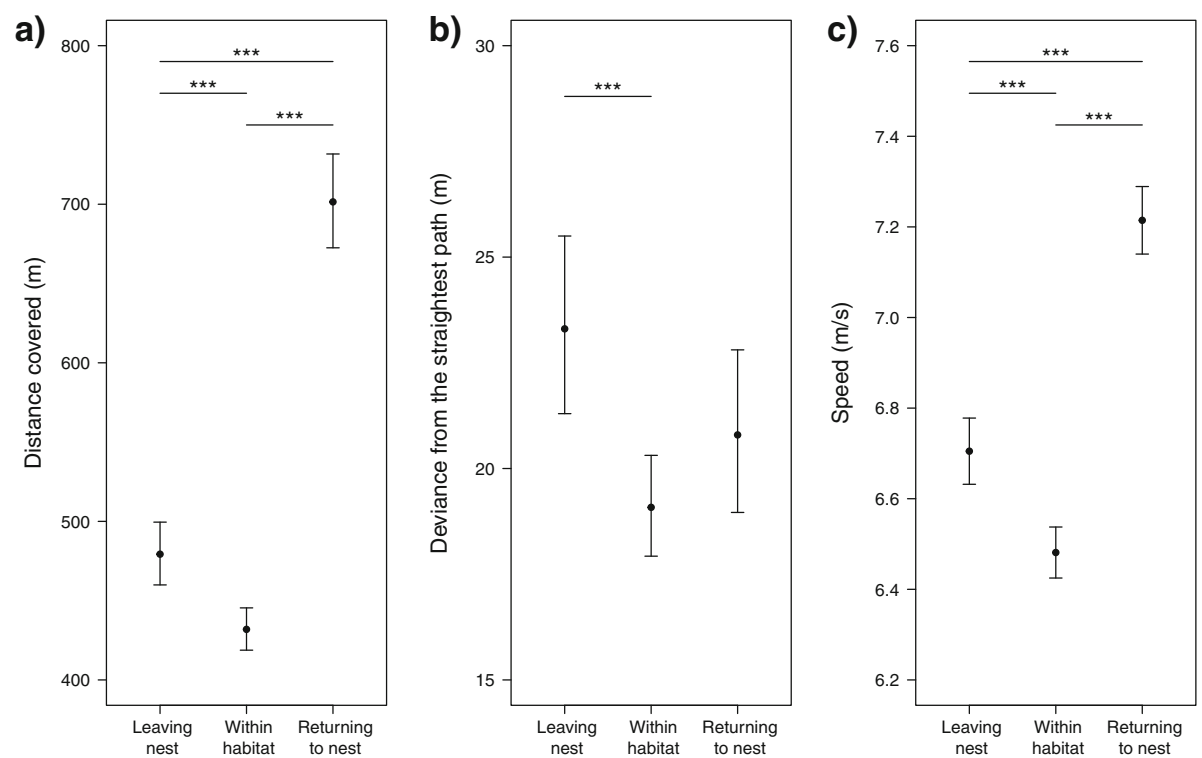

Fig. 4 Comparison of three type of commuting flights (leaving the nest, commuting within the habitat, and returning to the nest). Panel a) shows the distance covered, $\mathbf{b}$ ) the deviance from the straightest path, and c) the flight speed. For each flight type, the mean and $95 \%$ confidence intervals are shown

For hunting, barn owls displayed a strikingly contrasted selection pattern, with habitats being either preferred or avoided but not neutral (i.e. used at the same frequency as availability; Fig. 2d). Surprisingly, most habitats were actually selected as hunting grounds, with a wide range of vegetation structure, prey abundance and

Table 3 Difference between the three types of commuting leaving $(\mathrm{L})$ the nestbox, returning $(\mathrm{R})$ to it and within $(\mathrm{W})$ the habitat - in the distance covered, deviance from the straightest path and flight speed. Results from linear-mixed models including 12,503 tracks from 134 barn owls (owl identity set as random factor). The distance covered and the deviance from the straightest path were log-transformed

\begin{tabular}{cllll}
\hline Parameter & Estimate \pm SE & df & t-value & $p$ \\
\hline \multicolumn{5}{l}{ Distance covered } \\
L - W & $-0.104 \pm 0.017$ & 12,470 & -6.20 & $<0.001$ \\
L - R & $-0.381 \pm 0.022$ & 12,412 & 17.30 & $<0.001$ \\
W - R & $-0.485 \pm 0.0174$ & 12,461 & 27.93 & $<0.001$ \\
Deviance from the straightest path & & \\
L - W & $-0.199 \pm 0.039$ & 12,490 & -5.02 & $<0.001$ \\
L - R & $-0.114 \pm 0.052$ & 12,439 & -2.18 & 0.078 \\
W - R & $-0.086 \pm 0.041$ & 12,484 & 2.09 & 0.101 \\
Speed & & & & \\
L - W & $-0.224 \pm 0.028$ & 12,468 & -7.83 & $<0.001$ \\
L - R & $-0.510 \pm 0.037$ & 12,411 & 13.62 & $<0.001$ \\
W - R & $-0.733 \pm 0.029$ & 12,454 & 24.83 & $<0.001$ \\
\hline
\end{tabular}

agricultural regimes, reflecting the species' flexibility and adaptability. In a previous study, Arlettaz et al. (2010) showed a preference for cereals and intensive meadows (referred to as grassland in their study), arguing that vegetation structure was more important than prey availability. Our results confirm a selection for these habitats as hunting grounds, but also highlight the importance of extensive meadows and wildflower strips, the rarest but most preferred hunting habitats. The habitats selected for hunting differ strongly in vegetation height, and we found no seasonal selection differences in habitats with large fluctuations in vegetation structure throughout the year. Therefore, we could not find a limitation of habitat use based on vegetation structure as previously proposed $[7,51]$. Further research should investigate the interconnected effects of vegetation structure and prey density on hunting ground selection and success, while accounting for individual specific foraging strategies (on the wing or perched). In addition, as barn owls display a plumage colour polymorphism [23], upcoming studies should investigate morph-specific habitat preferences and foraging strategies, specifically in relation to night illumination [52].

Similarly to the other behavioural modes, commuting tracks bypassed the forested areas (Table 2). Flying over such tall structures as forest would possibly require a larger energetic investment for this usually low-flying bird [21]. Commuting tracks followed nearly straight paths and are hence optimised to reach their destination at high speed as directly as possible (Fig. 4). Since the 
flights to leave the nest box are shorter than those to return to it, owls might gradually move away from their nest box during the hunt. As central place foragers carrying one prey per nest visit, it would be advantageous for the owls to optimize their energy expenditure by starting to hunt close to the nest [53, 54]. Although most commuting flights were almost straight, some specific tracks deviated considerably from the shortest route (up to $991 \mathrm{~m}$ of difference), possibly due to fine-scale environmental or habitat structure variations. Avoiding adverse conditions such as strong head-winds or taking advantage of potential uplifts along tall structures could justify taking a longer route while optimizing energy expenditure [55].

\section{Conclusions}

This study highlights the need of behaviour-specific analyses to understand complex animal habitat preferences. The combination of the results unveils the barn owl as a generalist and opportunistic bird, with plastic behaviour to exploit a variety of open habitats in a farmland landscape. In comparison with a previous study [51], our results showed that barn owls select AES habitats, such as wildflower strips and extensive meadows, as hunting grounds. This supports the importance of such schemes to restore and maintain functional trophic chains in farmland, and stresses the need to promote such measures that are still rare and scattered. The quality of these areas dedicated to biodiversity could also be improved by increasing the connectivity between these plots $[56,57]$. In addition, their use by raptors could be enhanced through the installation of artificial poles in dense vegetation to favour the use of the sit-and-wait hunting technique [58, 59]. Future analyses should investigate the profitability of AES for farmland raptors, by translating AES availability and use into fitness benefits. Finally, our work demonstrates the importance of addressing habitat selection on a behaviour-specific perspective to account for the complex animal habitat selection patterns when proposing appropriate conservation plans.

\section{Supplementary Information}

The online version contains supplementary material available at https://doi. org/10.1186/s40462-021-00258-6.

Additional file 1: Table S1. For each habitat category are given the source of the data, and the object with the associated buffer used for creating the layers. Table S2. Correspondence between habitat classification and official agri-environment schemes (AES) categories. Table S3. Number of barn owl individuals included in habitat selection models. Table S4. Correspondence between habitat categories and the three dimensions of the non-metric multi-dimensional scaling (NMDS) performed on hunting selection estimates. Fig. S1. Step length and turning angle distributions for the perching, hunting and commuting behaviours. Fig. S2. Relation between hunting and commuting flight speeds and the behavioural event duration. Fig. S3. Distribution of night activity period duration, defined as the time between two daylight roosting events. Fig. S4. Proportion of activity time per night spent perching, hunting or commuting. Fig. S5. Home range size in relation to barn owl sex. Fig. S6. Non-metric multi-dimensional scaling (NMDS) model parametrization.

\section{Acknowledgements}

We thank C. Gémard, E. Mayor, S. Zurkinden, C. Plancherel, R. Sartori, C. Sahli, M. Déturche, M. Chèvre, J. Ehinger and N. Apolloni for their help in collecting field data, P. Béziers, L.M.San-Jose and R. Spaar for their support in the early development of the project.

\section{Authors' contributions}

All authors designed the project, A. Roulin and B. Almasi funded the research. R. Séchaud, K. Schalcher, A.P.Machado and C. Massa collected data. R. Séchaud and K. Schalcher analysed data. R. Séchaud wrote the manuscript, with significant contributions of all co-authors. The authors read and approved the final manuscript.

Funding

This study was financially supported by the Swiss National Science Foundation (grants no. 31003A_173178, to Alexandre Roulin) and Swiss Confederation (grants no. 2015.0788, to Carolina Massa).

\section{Availability of data and materials}

The GPS datasets generated and analysed during the current study are available in Movebank (www.movebank.org), under the project named "Barn owl (Tyto alba)" (ID 231741797). The habitats maps produced during the current study are available from the corresponding author on reasonable request.

\section{Declarations}

\section{Ethics approval and consent to participate}

This study meets the legal requirements of capturing, handling, and attaching GPS devices to barn owls in Switzerland (legal authorizations: VD and FR 2844 and 3213; capture and ringing permissions from the Federal Office for the Environment).

\section{Consent for publication}

Not applicable.

\section{Competing interests}

The authors declare that they have no competing interests.

\section{Author details}

${ }^{1}$ Department of Ecology and Evolution, University of Lausanne, Building Biophore, $\mathrm{CH}-1015$ Lausanne, Switzerland. ${ }^{2}$ Swiss Ornithological Institute, Seerose 1, 6204 Sempach, Switzerland. ${ }^{3}$ Instituto de Investigación e Ingeniería Ambiental, Laboratorio de Ecología de Enfermedades Transmitidas por Vectores, Universidad Nacional de San Martín, 25 de Mayo, 1650 San Martín, Buenos Aires, Argentina. ${ }^{4}$ Inmunova S.A., 25 de Mayo, 1650 San Martín, Buenos Aires, Argentina. ${ }^{5}$ Department of Migration, Max Planck Institute of Animal Behaviour, Am Obstberg 1, 78315 Radolfzell, Germany. ${ }^{6}$ Department of Biology, University of Konstanz, Universitätsstraße 10, 78464 Constance, Germany.

Received: 19 January 2021 Accepted: 31 March 2021

Published online: 21 April 2021

\section{References}

1. Green RE, Cornell SJ, Scharlemann JP, Balmford A. Farming and the fate of wild nature. Science (80- ). 2005;307:550-5 [cited 2018 Feb 8]. Available from: http://www.ncbi.nlm.nih.gov/pubmed/11303102.

2. Stoate C, Báldi A, Beja P, Boatman ND, Herzon I, van Doorn A, et al Ecological impacts of early 21 st century agricultural change in Europe - a review. J Environ Manag. 2009:91:22-46 [cited 2018 Feb 8]. Available from: https://www.sciencedirect.com/science/article/pii/S0301479709002448. 
3. Donald PF, Green RE, Heath MF. Agricultural intensification and the collapse of Europe's farmland bird populations. Proc R Soc Lond Ser B Biol Sci. 2001: 268:25-9 [cited 2020 Jun 24]. Available from: https://royalsocietypublishing. org/doi/10.1098/rspb.2000.1325.

4. Robinson RA, Sutherland WJ. Post-war changes in arable farming and biodiversity in Great Britain. J Appl Ecol. 2002;39:157-76[cited 2020 Mar 18]. Available from. https://doi.org/10.1046/j.1365-2664.2002.00695.x.

5. Kremen C, Williams NM, Thorp RW. Crop pollination from native bees at risk from agricultural intensification. Proc Natl Acad Sci U S A. 2002;99:16812-6 [cited 2020 Jun 24]. Available from: http://www.ncbi.nlm.nih.gov/ pubmed/12486221.

6. Kleijn D, Baquero RA, Clough Y, Díaz M, Esteban J, Fernández F, et al. Mixed biodiversity benefits of Agri-environment schemes in five European countries. Ecol Lett. 2006;9:243-54[cited 2018 Feb 8]. Available from. https:// doi.org/10.1111/j.1461-0248.2005.00869.x.

7. Aschwanden J, Birrer S, Jenni L. Are ecological compensation areas attractive hunting sites for common kestrels (Falco tinnuculus) and longeared owls (Asio otus)? J Ornithol. 2005;146(3):279-86. https://doi.org/10.1 007/s10336-005-0090-9.

8. Zingg S, Ritschard E, Arlettaz R, Humbert JY. Increasing the proportion and quality of land under Agri-environment schemes promotes birds and butterflies at the landscape scale. Biol Conserv. 2019;231:39-48. https://doi. org/10.1016/j.biocon.2018.12.022.

9. Wade MR, Gurr GM, Wratten SD. Ecological restoration of farmland: Progress and prospects. Philos Trans R Soc B Biol. 2008:831-47 [cited 2020 Aug 31]. Available from: https://royalsocietypublishing.org/doi/abs/10.1098/rstb.2 007.2186.

10. Roever $\mathrm{CL}$, Beyer HL, Chase MJ, van Aarde RJ. The pitfalls of ignoring behaviour when quantifying habitat selection. Roura-Pascual N, editor Divers Distrib. 2014;20:322-33[cited 2020 Jul 29]. Available from. https://doi. org/10.1111/ddi.12164.

11. Dussault C, Quellet JP, Courtois R, Huot J, Breton L, Jolicoeur H. Linking moose habitat selection to limiting factors. Ecography (Cop). 2005;28:61928 [cited 2020 Oct 28]. Available from: https://onlinelibrary.wiley.com/doi/ full/10.1111/j.2005.0906-7590.04263.x.

12. Smith LM, Hupp JW, Ratti JT. Habitat use and home range of gray partridge in eastern South Dakota. J Wildl Manag. 1982;46:580-7 [cited 2018 Feb 8]. Available from: http://www.jstor.org/stable/3808548? origin=crossref.

13. Stamps JA, Davis JM. Adaptive effects of natal experience on habitat selection by dispersers. Anim Behav. 2006;72:1279-89 [cited 2018 Feb 8]. Available from: https://www.sciencedirect.com/science/article/pii/S00033472 06002855

14. Mayor SJ, Schneider DC, Schaefer JA, Mahoney SP. Habitat selection at multiple scales. Ecoscience. 2009;16:238-47 [cited 2017 Feb 10]. Available from: https://pubag.nal.usda.gov/pubag/article.xhtml?id=1267421.

15. McGarigal K, Wan HY, Zeller KA, Timm BC, Cushman SA. Multi-scale habitat selection modeling: a review and outlook. Landsc Ecol. 2016;31:1161-75 [cited $2020 \mathrm{Jul}$ 8]. Available from: https://link.springer.com/article/10.1007/s1 0980-016-0374-x.

16. Fauchald $P$, Tveraa T. Using fisrt-passage time in the analysis of arearestricted search and habitat selection. Ecology. 2003;84:282-8 [cited 2018 Feb 8]. Available from: http://onlinelibrary.wiley.com/doi/10.1890/0012 9658(2003)084\%5B0282:UFPTIT\%5D2.0.CO;2/abstract.

17. Jonsen I, Myers R, James M. Identifying leatherback turtle foraging behaviour from satellite telemetry using a switching state-space model. Mar Ecol Prog Ser. 2007;337:255-64 [cited 2020 Aug 31]. Available from: http:// www.int-res.com/abstracts/meps/v337/p255-264/.

18. Garriga J, Palmer JRB, Oltra A, Bartumeus F. Expectation-maximization binary clustering for Behavioural annotation. PLoS One. 2016;11:e0151984 [cited 2018 Jan 2]. Available from: http://journals.plos.org/plosone/article/file?id= 10.1371/journal.pone.0151984\&type=printable.

19. Suraci JP, Frank LG, Oriol-Cotterill A, Ekwanga S, Williams TM, Wilmers CC. Behavior-specific habitat selection by African lions may promote their persistence in a human-dominated landscape. Ecology. 2019;100:e02644 [cited 2020 Aug 31]. Available from: https://onlinelibrary.wiley.com/doi/a bs/10.1002/ecy.2644.

20. De Bruijn O. Population ecology and conservation of the barn owl Tyto alba in farmland habitats in liemers and achterhoek (the Netherlands). ARDEA. 1994:1-109 [cited 2018 Feb 8]. Available from: http://www.avibirds.com/pdf/ K/Kerkuil3.pdf.
21. Taylor I. Barn owls: predator-prey relationships and conservation: Cambridge University Press; 1994.

22. Frey C, Sonnay C, Dreiss A, Roulin A. Habitat, breeding performance, diet and individual age in Swiss barn owls (Tyto alba). J Ornithol. 2010;152:27990[cited 2014 Dec 20]. Available from:. https://doi.org/10.1007/s10336-0100579-8.

23. Roulin A. Tyto alba barn owl. BWP Updat. 2002;4:115-38 [cited 2020 Jun 29]. Available from: https://serval.unil.ch/notice/serval:BIB_2CBA948E4914.

24. QGIS Development Team, QGIS. QGIS geographic information system; 2017. Open Source Geospatial Foundation.

25. Almasi B, Roulin A, Jenni L. Corticosterone shifts reproductive behaviour towards self-maintenance in the barn owl and is linked to melanin-based coloration in females. Horm Behav. 2013;64(1):161-71. https://doi.org/10.101 6/j.yhbeh.2013.03.001.

26. R Core Team. R: a language and environment for statistical computing. Vienna: R Foundation for Statistical Computing; 2018. URL https://www.Rproject.org/

27. Worton BJ. Kernel methods for estimating the utilization distribution in home-range studies. Ecology. 1989;70:164-8[cited 2018 Jan 2]. Available from. https://doi.org/10.2307/1938423.

28. Calabrese JM, Fleming CH, Gurarie E. Ctmm : an R package for analyzing animal relocation data as a continuous-time stochastic process. Freckleton R, editor. Methods Ecol Evol. 2016;7:1124-32[cited 2018 Jan 2]. Available from. https://doi.org/10.1111/2041-210X.12559.

29. Fleming $\mathrm{CH}$, Fagan WF, Mueller T, Olson KA, Leimgruber $\mathrm{P}$, Calabrese JM. Rigorous home range estimation with movement data: a new autocorrelated kernel density estimator. Ecology. 2015;96:1182-8[cited 2017 Jan 16]Available from:. https://doi.org/10.1890/14-2010.1.

30. Kuznetsova A, Brockhoff PB, Christensen RHB. ImerTest package: tests in linear mixed effects models. J Stat Softw. 2017;82:1-26 [cited 2020 Dec 3]. Available from: https://www.jstatsoft.org/index.php/jss/article/view/v082i13/ v82i13.pdf.

31. Manly BFJ, McDonald LL, Thomas DL, McDonald TL, Erickson WP. Resource selection by animals : statistical design and analysis for field studies: Kluwer Academic Publishers; 2002

32. Calenge $\mathrm{C}$. The package "adehabitat" for the R software: a tool for the analysis of space and habitat use by animals. Ecol Model. 2006;197(3-4):5169. https://doi.org/10.1016/j.ecolmodel.2006.03.017.

33. Thurfjell H, Ciuti S, Boyce MS. Applications of step-selection functions in ecology and conservation. Mov Ecol. 2014;2:4 [cited 2019 May 8]. Available from: https://movementecologyjournal.biomedcentral.com/articles/10.11 86/2051-3933-2-4

34. Signer J, Fieberg J, Avgar T. Animal movement tools (amt): R package for managing tracking data and conducting habitat selection analyses. Ecol Evol. 2019;9:880-90[cited 2020 Jul 21]. Available from. https://doi.org/10.1 002/ece3.4823.

35. Duchesne T, Fortin D, Rivest L-P. Equivalence between step selection functions and biased correlated random walks for statistical inference on animal movement. Petit O, editor. PLoS One. 2015;10:e0122947[cited 2020 Jul 21]. Available from. https://doi.org/10.1371/journal.pone.0122947.

36. Avgar T, Potts JR, Lewis MA, Boyce MS. Integrated step selection analysis: bridging the gap between resource selection and animal movement. Börger L, editor. Methods Ecol Evol. 2016;7:619-30[cited 2019 May 8]. Available from. https://doi.org/10.1111/2041-210X.12528.

37. Minchin PR. An evaluation of the relative robustness of techniques for ecological ordination. Theory Model Veg Sci. 1987:89-107[cited 2020 Aug 5]. Available from:. https://doi.org/10.1007/978-94-009-4061-1_9.

38. Dixon P. VEGAN, a package of $R$ functions for community ecology. J Veg Sci. 2003:927-30 [cited 2020 Aug 5]. Available from: https://onlinelibrary. wiley.com/doi/full/10.1111/j.1654-1103.2003.tb02228.x.

39. Cushman SA, Lewis JS. Movement behavior explains genetic differentiation in American black bears. Landsc Ecol. 2010;25:1613-25[cited 2020 Jul 31]. Available from:. https://doi.org/10.1007/s10980-010-9534-6.

40. Brandt T, Seebass C. In: Wiesbaden, editor. Die Schleiereule: AULA-Verlag; 1994. [cited 2020 Nov 25]. Available from: https://www.amazon.de/DieSchleiereule-heimlichen-Kulturfolgers-AULA-Verlag/dp/3891045417.

41. Michelat D, Giraudoux P. Dimension du domaine vital de la chouette effraie Tyto alba pendant la nidification. Alauda. 1991;59:137-42.

42. Roulin A. Offspring desertion by double-brooded female barn owls (Tyto Alba). Auk. 2002:119(2):515-9. https://doi.org/10.1093/auk/119.2.515. 
43. Roulin A. Nonrandom pairing by male barn owls (Tyto alba) with respect to a female plumage trait. Behav Ecol. 1999;10(6):688-95. https://doi.org/10.1 093/beheco/10.6.688.

44. Béziers $P$, Roulin A. Double brooding and offspring desertion in the barn owl Tyto alba. J Avian Biol. 2016;47(2):235-44. https://doi.org/10.1111/jav. 00800.

45. Lausen CL, Barclay RMR. Benefits of living in a building: big brown bats (Eptesicus fuscus) in rocks versus buildings. J Mammal. 2006;87:362-70 [cited 2020 Sep 3]. Available from: https://academic.oup.com/jmammal/articlelookup/doi/10.1644/05-MAMM-A-127R1.1.

46. Blair R. The effects of urban sprawl on birds at multiple levels of biological organization. Ecol Soc Soc. 2004;9(4). https://www.jstor.org/stable/26267695. Accessed 9 Apr 2021.

47. Jaksic FM, Carothers JH. Ecological, morphological, and bioenergetic correlates of hunting mode in hawks and owls. Ornis Scand. 1985;16(3):16572. https://doi.org/10.2307/3676627.

48. Kullberg C. Strategy of the pygmy owl while hunting avian and mammalian prey. Ornis Fenn. 1995;72:72-8.

49. Hopcraft JGC, Sinclair ARE, Packer C. Planning for success: Serengeti lions seek prey accessibility rather than abundance. J Anim Ecol. 2005;74:55966[cited 2021 Mar 10]. Available from. https://doi.org/10.1111/j.1365-2656.2 005.00955.x.

50. Kross SM, Bourbour RP, Martinico BL. Agricultural land use, barn owl diet, and vertebrate pest control implications. Agric Ecosyst Environ. 2016;223: 167-74 [cited 2016 Mar 24]. Available from: http://www.sciencedirect.com/ science/article/pii/S0167880916301293.

51. Arlettaz R, Krähenbühl M, Almasi B, Roulin A, Schaub M. Wildflower areas within revitalized agricultural matrices boost small mammal populations but not breeding barn owls. J Ornithol. 2010;151:553-64[cited $2016 \mathrm{Mar}$ 25]. Available from:: https://doi.org/10.1007/s10336-009-0485-0.

52. San-Jose LM, Séchaud R, Schalcher K, Judes C, Questiaux A, Oliveira-Xavier $A$, et al. Differential fitness effects of moonlight on plumage colour morphs in barn owls. Nat Ecol Evol. 2019;3:1331-40[cited 2020 Jul 24]. Available from. https://doi.org/10.1038/s41559-019-0967-2.

53. Patenaude-Monette $\mathrm{M}$, Bélisle $\mathrm{M}$, Giroux J-F. Balancing energy budget in a central-place forager: which habitat to select in a heterogeneous environment? Sears M, editor. PLoS One. 2014;9:e102162[cited 2021 Mar 10]. Available from:. https://doi.org/10.1371/journal.pone.0102162.

54. Charnov EL. Optimal foraging, the marginal value theorem. Theor Popul Biol. 1976;9(2):129-36. https://doi.org/10.1016/0040-5809(76)90040-X.

55. Péron $\mathrm{G}$, Fleming $\mathrm{CH}$, Duriez $\mathrm{O}$, Fluhr J, Itty C, Lambertucci $\mathrm{S}$, et al. The energy landscape predicts flight height and wind turbine collision hazard in three species of large soaring raptor. Bauer S, editor. J Appl Ecol. 2017;54: 1895-906[cited 2020 Aug 9]. Available from:. https://doi.org/10.1111/1365-2 664.12909

56. Frey-Ehrenbold A, Bontadina F, Arlettaz R, Obrist MK. Landscape connectivity, habitat structure and activity of bat guilds in farmlanddominated matrices. Pocock M, editor. J Appl Ecol. 2013;50:252-61 [cited 2021 Mar 10]. Available from:. https://doi.org/10.1111/1365-2664.12034.

57. Aviron $S$, Lalechère $E$, Duflot $R$, Parisey N, Poggi $S$. Connectivity of cropped vs. semi-natural habitats mediates biodiversity: a case study of carabid beetles communities. Agric Ecosyst Environ. 2018;268:34-43.

58. Kay BJ, Twigg LE, Korn TJ, Nicol HI. The use of artificial perches to increase predation on house mice (Mus domesticus) by raptors. Wildl Res. 1994;21: 739-43 [cited 2021 Mar 10]. Available from: https://www.publish.csiro.au/wr/ wr9940095.

59. Widen P. Habitat quality for raptors: a field experiment. J Avian Biol JSTOR. 1994;25:219

\section{Publisher's Note}

Springer Nature remains neutral with regard to jurisdictional claims in published maps and institutional affiliations.

Ready to submit your research? Choose BMC and benefit from:

- fast, convenient online submission

- thorough peer review by experienced researchers in your field

- rapid publication on acceptance

- support for research data, including large and complex data types

- gold Open Access which fosters wider collaboration and increased citations

- maximum visibility for your research: over $100 \mathrm{M}$ website views per year

At BMC, research is always in progress.

Learn more biomedcentral.com/submissions 